\title{
Barack Obama e Donald Trump: a China na grande estratégia dos Estados Unidos (2009-2020)
}

\author{
Barack Obama and Donald Trump: China in US grand \\ strategy (2009-2020)
}

\section{Barack Obama y Donald Trump: China en la grande estrategia estadounidense (2009-2020)}

Rúbia Marcussi Pontes

DOI: 10.5752/P.2317-773X.2021v9.n3.p131

Recebido em: 04 de agosto de 2020

Aprovado em: 04 de outubro de 2021
1. Doutoranda e mestra em Ciência Política pela Universidade Estadual de Campinas (UNICAMP), professora de Relações Internacionais das Faculdades de Campinas (FACAMP), pesquisadora do INCT-INEU. Campinas, Brasil. ORCID: https://orcid.org/0000-0002-0230-0600. Email: rubiamarcussi@gmail.com

\begin{abstract}
RESUMO
O artigo analisa a política dos Estados Unidos (EUA) para a República Popular da China (RPC), nos governos de Barack Obama (2009-2016) e de Donald Trump (2017-2020). Para tanto, baseia-se na discussão teórica sobre grande estratégia, entendida como as coordenadas gerais de atuação de um Estado no sistema internacional, e sobre a operacionalização de seu estudo, pelo marco das políticas setoriais, cuja compreensão, sugere-se, deve ser realizada em relação à política global, ou seja, em relação à grande estratégia. É nesse sentido que a política dos EUA para a China é compreendida. Busca-se discutir seus principais elementos históricos e, a partir da análise documental e de fontes secundárias, defende-se a tese de que há, tanto no governo Obama quanto Trump, o fortalecimento da visão e do apoio bipartidário às medidas mais duras para com a China, com mudança de meios, mas não de fins, sob Trump.
\end{abstract}

Palavras-chave: Grande Estratégia. Estados Unidos. Barack Obama. Donald Trump. China.

\begin{abstract}
The article analyses the United States' policy to the People's Republic of China during Barack Obama (2009-2016) and Donald Trump (2017-2020) administrations. In order to do so, the article is based on the theoretical debate about grand strategy, which is understood as a state's general guidelines in the international system, and its sectorial policies, which should be understood, as suggested, in relation to the global policy expressed in the grand strategy. It is in this sense that US China policy should be understood in this study. The article also discusses the historical elements of this policy and, through document analysis and secondary sources, it argues that there is, in Obama and Trump administrations, the hardening of China policy with a growing bipartisanship consensus, with a change of tactics, but not of objectives, under Trump.
\end{abstract}

Keywords: Grand Strategy. United States. Barack Obama. Donald Trump. China. 


\section{RESUMEN \\ El artículo hace un análisis de la política de los Estados Unidas (EEUU) para la República Popular de China (RPC), en los gobiernos de Barack Obama (2009- 2016) y de Donald Trump (2017-2020). Para eso, el artículo está basado en la discusión teórica acerca la gran estrategia, comprendida como una de las coordenadas generales de actuación de un Estado en el sistema internacional, y acerca la operacionalización de su estudio, a través de las políticas sectoriales, cuya comprensión, en que se sugiere, debe a ser realizada en relación con la política global; o sea, en relación a la gran estrategia. Es en ese sentido que la política de EEUU para China es entendida. Se busca discutir sus principales ele- mentos históricos y, a partir del análisis documental y de las fuentes secundarias, se defiende la tesis de que haya, tanto en el gobierno Obama cuanto Trump, el fortalecimiento de la visión y del apoyo bipartidista a las medidas más duras para con China, con cambios de medios, pero no de fines, bajo Trump.}

Palabras clave: Gran Estrategia. Estados Unidos. Barack Obama. Donald Trump. China.

Introdução

O presente artigo busca realizar uma análise da política dos Estados Unidos (EUA) para a República Popular da China (RPC) nos governos de Barack Obama (2009-2016) e Donald Trump (2017-2020). Parte-se da discussão sobre grande estratégia, entendida como as coordenadas gerais que pautam a atuação de um Estado no sistema internacional, e sua composição por políticas setoriais, cuja compreensão, sugere-se, deve ser realizada em relação à política global. É nesse sentido que a política dos EUA para a China é compreendida aqui. Busca-se discutir quais foram os principais elementos históricos dessa política e defende-se a tese de que há, tanto no governo Obama quanto Trump, o fortalecimento da visão e do apoio bipartidário às medidas mais duras para com a China, com mudança de meios, mas não de fins, sob Trump.

Para tanto, o primeiro tópico do artigo resgata o debate sobre grande estratégia e a operacionalização de seu estudo. As origens históricas do conceito e seu desenvolvimento posterior são brevemente elencados para se discutir como analisar uma grande estratégia. Argumenta-se que esta pode ser entendida como as coordenadas gerais que pautam a conduta de um Estado e que, portanto, é composta por políticas setoriais, ou particulares, que a sustentam e que, juntas, imprimem legitimidade e coerência à grande estratégia, no longo prazo.

Tal proposição é essencial para a compreensão do pano de fundo da grande estratégia dos EUA e, de forma específica, sua política para a China. Esse é o objetivo do segundo tópico, que resgata os principais marcos da grande estratégia estadunidense e como a China esteve inscrita nela, com destaque para as políticas de contenção e de engajamento daquele Estado pelos EUA. Entende-se que o estudo de tais dinâmicas é essencial para uma melhor compreensão do período proposto para análise, no sentido que tais dinâmicas marcam a política dos EUA para China, de forma definitiva, e continuam presentes no debate contemporâneo.

Por fim, o terceiro e quarto tópicos do artigo buscam analisar a política propriamente dita dos EUA para a China, nos governos de Ba- 
rack Obama e de Donald Trump, respectivamente. Utiliza-se de análise documental e, principalmente, revisão da literatura sobre os principais elementos da política nesse período, de forma a explicar a continuidade em termos de iniciativas e posicionamentos para constranger a China, com um crescente consenso bipartidário doméstico nesse sentido, apesar da mudança de meios sob Trump. Tal encaminhamento busca fortalecer a análise de como as decisões atuais da política para a China, entendidas como mais assertivas, não são a mera expressão das ambições de um líder, mas, sim, esforços na busca pela manutenção do poderio estadunidense no sistema internacional.

0 debate sobre grande estratégia e seus componentes

Antes de adentrar na análise da política dos Estados Unidos (EUA) para a China propriamente dita, é necessário discutir o conceito de grande estratégia e a operacionalização de seu estudo através de políticas setoriais. Assim, esse tópico tem como objetivo a discussão da temática da grande estratégia. Busca-se resgatar as origens do conceito para, em seguida, observar as definições que se desenvolveram de forma mais contemporânea e as relações entre grande estratégia e política externa. Discute-se também a operacionalização do estudo de uma grande estratégia, delineando uma abordagem alternativa, que olha para a política global de um Estado, a partir de políticas particulares, que sustentam uma grande estratégia.

O conceito de estratégia está originalmente relacionado ao léxico militar, como o conjunto de operações de guerra, em que a ação de uma parte levará à reação da outra, que, por sua vez, poderá modificar seu comportamento posteriormente e, assim por diante, em uma ação complexa entre sujeitos com objetivos distintos, chamada de ação estratégica. Como aponta Cruz (2012, p. 5-6), tal ação é incompatível com planos rígidos, dada a relação entre partes com vontades contrapostas, que constantemente precisam reavaliar os resultados alcançados e seus objetivos diante da ação do outro.

Diretamente relacionado ao conceito de estratégia, o conceito de grande estratégia, por sua vez, foi originalmente conceituado por Liddell Hart (1967), militar e teórico inglês, como uma estratégia em nível superior, cuja grande característica seria a coordenação e o direcionamento de recursos para a conquista do objeto político da guerra. Segundo Hart (1967, p. 321, tradução nossa), "como a tática é uma aplicação da estratégia em um plano inferior, a estratégia é, portanto, uma aplicação em um plano inferior de uma grande estratégia ${ }^{20}$. Nesse sentido, uma grande estratégia deveria tanto calcular quanto desenvolver os recursos econômicos necessários para atender aos objetivos propostos e às suas forças combatentes, bem como ir além e empregar outros instrumentos, como o poder financeiro e a pressão diplomática e comercial, para atender aos objetivos propostos.

Tal conceitualização é fruto das experiências das Primeira e Segunda Guerras Mundiais, com a coordenação, sem precedentes, de bem-sucedidas iniciativas militares, diplomáticas, políticas e econômicas dos Aliados, o que garantiu as vitórias nas guerras e marcou a popularização
2. Do original: "As tactics is an application of strategy on a lower plane, so strategy is an application on a lower plane of grand strategy" (HART, 1967, p. 321). 
do termo grande estratégia para um amplo público. Nesse contexto, o debate mais contemporâneo sobre grande estratégia passa por perspectivas que ainda primam pelo seu aspecto militar, embora de forma mais reduzida, enquanto outras a analisam como a maior expressão de política externa de um Estado.

Art (2009, p. 1) é um expoente da primeira vertente e entende a grande estratégia como "(...) as formas com as quais um Estado, no caso os EUA, emprega seu poderio militar para apoiar seus interesses nacionais". É interessante notar que, nessa perspectiva, a grande estratégia é diferente de política externa: esta elencaria quais são os interesses nacionais que o Estado deve perseguir, bem como os instrumentos (econômicos, políticos, militares, diplomáticos, etc.), para garantir que o Estado busque e proteja esses interesses. A grande estratégia já teria um foco específico: ela se concentra em como o instrumental militar pode ser mais bem utilizado, para apoiar os objetivos de política externa de um Estado.

Outros analistas, por sua vez, já entendem a grande estratégia como o maior nível, ou como a "arquitetura intelectual", da política externa. Van Apeldoorn e De Graaff (2016, p. 7) operam nesse sentido, com a grande estratégia definindo objetivos de longo prazo e os meios para alcançá-los, o que implica a utilização de diversos instrumentos de curto prazo, para priorizar e alcançar tais grandes objetivos. A grande estratégia não é entendida como um mero apanhado de interesses nacionais e vai além do interesse militar, incluindo questões geopolíticas e geoeconômicas.

Nesse sentido, a coerência no planejamento e na implementação da grande estratégia é essencial: ela não é um mero cômputo de interesses de grupos de pressão que influenciam os tomadores de decisão; mas, ao mesmo tempo, os tomadores de decisão não estão isolados e precisam lidar com os esforços feitos pelas administrações anteriores e com eventos contingenciais. Dessa forma, a variação nos instrumentos utilizados para a implementação da grande estratégia no curto prazo assume caráter de destaque, mas a grande estratégia permanece, com propósito e coerência.

Posto isso, é importante ressaltar que o entendimento de grande estratégia como o maior nível de política externa, nos moldes propostos por Apeldoorn e De Graaff (2016), está alinhado ao entendimento do artigo. E é justamente com isso em mente que, agora, será discutida a operacionalização do estudo de uma grande estratégia. Busca-se combinar os elementos de abordagens clássicas, mas também delinear uma abordagem alternativa, que olha para a política global de um Estado, a partir de políticas setoriais.

Uma das perspectivas possíveis para o estudo da grande estratégia, diante da crescente complexidade que pauta as sociedades, seria a da tradição realista em Relações Internacionais. Tal perspectiva está fundamentada na ideia de que os Estados são as unidades máximas de poder e únicos atores no sistema internacional, além de serem movidos por interesses racionais; os Estados seriam, assim, atores homogêneos, que concentram o interesse nacional em decisões coerentes, na busca pela sobrevivência (HILL, 2003, p. 7-9).

Outra perspectiva seria a do modelo de política burocrática, que analisa as decisões estatais como resultantes de barganhas entre grupos 
de interesses. Esse modelo de análise não enxerga um ator unitário, mas, sim, vários atores que atuam não apenas com um único objetivo estratégico em mente, mas, diversos - os quais poderiam variar entre distintas concepções de objetivos nacionais, organizacionais e pessoais (ALLISON, 1969, p. 707). Nessa perspectiva, líderes políticos ocupam o topo hierárquico de comando e atuam com outros líderes, que ocupam posições cruciais em organizações burocráticas estatais, com o compartilhamento de poder, de acordo com essa estrutura (ALLISSON, 1969, p. 707-708).

Outra perspectiva, por fim, seria a do processo organizacional, segundo o qual as decisões são frutos das rotinas das organizações que compõem o Estado, que não é, portanto, um ator unitário. Nessa linha de raciocínio, as organizações são encaradas como verdadeiras unidades de ação estratégica, em que "as estratégias não resultam da ação deliberada de grupos ou indivíduos, mas "emergem" como padrões cristalizados de comportamento” (CRUZ, 2012, p. 13-14). Cada organização é responsável por um conjunto de problemas, agindo de forma quase independente em sua resolução, com baixo nível de interferência de líderes governamentais na performance de rotinas ou padrões de coordenação, que vão se cristalizando (ALLISSON, 1969, p. 698).

Embora tais perspectivas possuam aspectos de relevância, ao se analisar política e grande estratégia, é necessário expandir o escopo. Afinal, não se trata de assumir que o Estado é unitário, na busca por um objetivo geral, ou excessivamente fragmentado em seus processos de tomada de decisão, cujos resultados seriam frutos de barganhas políticas internas. Além disso, tratar uma estratégia como padrão de comportamento é, a priori, uma redundância. Ainda, segundo a perspectiva organizacional, a estratégia não é um atributo do sistema estatal, mas das organizações que o compõem - o que não ajuda no entendimento de políticas de caráter generalizante.

Entretanto, um aspecto do paradigma organizacional é interessante para a construção de uma abordagem alternativa do estudo da grande estratégia, a saber: a ênfase nos procedimentos padrões e nos programas, como fonte de coordenação para a ação de milhares de indivíduos que lidam, com certa independência, com "situações-problema" de forma rotineira. A grande estratégia pode ser analisada, a partir de tal aspecto, pois abarca a coordenação de atividades de inúmeros agentes em um processo no qual "o Estado observa e avalia suas operações e comunica-se permanentemente a respeito delas com seus funcionários e com o conjunto da sociedade" (CRUZ, 2012, p. 16), em uma verdadeira interação estratégica, numa cadeia de ações e reações.

Nesse sentido, a grande estratégia pode ser entendida, ainda segundo Cruz (2012, p. 18), "como as orientações gerais que pautam a conduta de um Estado, em sua relação com o mundo". Aqui, é importante marcar que estas são coordenadas mais ou menos gerais, dado o elemento da intencionalidade como parte integrante da ação estratégica, mas que não são compreendidas como resultantes de planos milimetricamente calculados. Além disso, essas coordenadas são, sempre, o fruto de uma assimetria de poder entre os atores, com alguns sendo privilegiados, enquanto outros são marginalizados em determinados momentos. 
Tais orientações gerais são realizadas a partir de políticas particulares, cuja análise deve ser sempre realizada em relação ao marco geral, no sentido de buscar a compatibilização e integração de políticas que são funcional e espacialmente diferenciadas, mas também partes cruciais de uma grande estratégia. Os elementos da intencionalidade e do entrechoque de ideias e de interesses do processo político não são abandonados nessa perspectiva: na realidade, tais categorias permitem o olhar focalizado para o processo de formulação e de implementação de uma política particular, sem perder do horizonte as coordenadas gerais que pautam a conduta de um Estado no sistema internacional, bem como suas transformações, ao longo do tempo.

A noção de referencial normativo de Muller (1985) é interessante nesse quadro analítico, compreendido como a representação de um setor (ou área de problema) e de sua relação com a sociedade. O referencial normativo é composto pelos referenciais global e setorial, que são categorias para análise, e pelos elementos de integração do setorial no global. O referencial global não é um projeto perfeitamente integrado, mas sim a imagem em torno da qual as representações setoriais se organizam. Ele demarca um campo de disputas, estabelecendo relações hierárquicas entre suas normas internas. O referencial setorial, por sua vez, é caracterizado pela percepção que se tem de um dado setor dos grupos dominantes, que expressam sua liderança (MULLER, 1985, p. 170).

Os conflitos não são ausentes nessa perspectiva, pelo contrário: ressalta-se a complexidade da realidade e o entrechoque de ideias e interesses entre os atores. Porém, ainda segundo Muller (1985), isso não elimina suas relações e os elementos de integração do setorial no global, pois é a representação entre esses dois mediadores que estrutura uma política, hierarquizando seus objetivos e determinando o seu alcance social e geográfico.

É nessa dinâmica entre particular e geral, entre setorial e global, que as políticas são delineadas e implementadas por um Estado, em um processo em que as forças sociais e políticas se reposicionam constantemente. Em momentos de crise, a não correspondência na dinâmica entre o setorial e o global é mais evidente, com as diferenças de interesses mais reveladas na arena de embate político. Mas, em situações mais rotineiras, a coerência predomina na dinâmica.

Tal quadro de análise é essencial para o estudo da grande estratégia, no sentido de que ela não é um plano formulado e seguido à risca pelos dirigentes de um Estado: ela é melhor compreendida como se fossem coordenadas gerais que pautam as relações estatais, a partir de políticas particulares. O trato da conjuntura é essencial em qualquer governo, mas os acontecimentos conjunturais também estão inseridos em uma cadeia de acontecimentos na qual os atores se posicionam e se reposicionam de forma constante, em uma lógica de ação estratégica. É com tais elementos em mente que o próximo tópico discute os grandes marcos da grande estratégia dos EUA e, mais especificamente, como a China se insere nela como uma política setorial, sendo reproduzida com o passar do tempo, e sofrendo mudanças, de acordo com os interesses e objetivos impressos à grande estratégia dos EUA. 
A China na grande estratégia dos EUA: perspectiva histórica

Este tópico tem como objetivo a análise das origens da grande estratégia dos Estados Unidos (EUA) e sua consolidação ao longo do tempo, embora sempre de maneira relacional ao marco da política setorial para a China. Resgata-se a estratégia de contenção do socialismo e de isolamento da China, nos anos 1950, e o subsequente desgaste de tal política e sua substituição pelo engajamento da China ao sistema internacional, nos anos 1970 e 1980. Tal caminho busca ressaltar determinados momentos que afetaram a grande estratégia dos EUA como um todo e, mais especificamente, a política setorial para a China, até a percepção mais contemporânea desse Estado como uma ameaça aos objetivos e interesses dos EUA.

As origens da grande estratégia estadunidense datam da conclusão da Guerra Civil e da reconstituição do pacto entre as elites regionais, em um projeto de nação unificada, pelo qual os EUA poderiam efetivar sua pretensão de projeção de seu poder, tanto no continente mais imediato, quanto em outras partes do mundo. É com esse panorama que Williams (2009, p. 15) afirma que, desde o século XIX, os EUA seguiram uma política chamada, por ele, de imperialismo das portas abertas (imperialism of the open door). Sua premissa era de que o bem-estar doméstico da nação dependeria, cada vez mais, da constante expansão econômica para além-mar.

Como ressaltado por Pecequilo (2013, p. 3), a política das portas abertas marcou a busca estadunidense por novos mercados através do estabelecimento de relações comerciais livres e iguais entre as nações, sendo compreendida como o centro da grande estratégia estadunidense. Essa expansão ocorreu, principalmente, para a América Latina, mas também para o chamado "extremo oriente", com destaque para a presença estadunidense na China, com laços comerciais garantidos pelos tratados de Wanghia, de 1844, e de Tianjin, de 1858.

LaFeber (1994, p. 103) afirma que tais tratados marcaram as relações entre os dois países por quase um século. Eles atendiam ao duplo objetivo da política dos EUA para a China de conquistar os mercados comercial e religioso, o que foi transposto na política de portas abertas. Os EUA alcançaram a marca de US\$ 15 milhões, entre 1895 e 1900, com as exportações para a China, destacando-se a importância do comércio entre tais nações para a indústria de algodão manufatureira estadunidense (LAFEBER, 1994, p. 218; VAN APELDOORN; DE GRAAFF, 2016, p. 41).

O período das Guerras Mundiais foi essencial para que os EUA determinassem, no século $\mathrm{XX}$, as principais linhas de orientação de sua grande estratégia e de suas relações exteriores. Nesse sentido, foi no Pós-Segunda Guerra Mundial em que os EUA emergiram como o principal poder na arena internacional e passassem a articular sua visão da política de portas abertas, em um nível verdadeiramente global, tornando-a, definitivamente, a base de sua grande estratégia (VAN APELDOORN; DE GRAAFF, 2016, p. 47). A organização do sistema internacional do Pós-Guerra, assim, foi um momento em que a diplomacia norte-americana se empenhou para garantir que seus interesses políticos e econômicos fossem cristalizados em organizações e regimes internacionais. 
Nesse contexto, as divergências entre os EUA e União Soviética (URSS) ganhavam proeminentes contornos até o anúncio, pelos EUA, da Doutrina Truman, em julho de 1947. Os EUA passaram a atuar visando à contenção da URSS e do socialismo, buscando manter a preponderância do modelo capitalista no contexto da Guerra Fria. Nesse panorama, os riscos de o socialismo ganhar o Estado chinês eram cada vez maiores, levando em consideração a disputa pelo poder que ocorria na guerra civil chinesa, travada entre o Kuomintang (KMT), liderado por Chiang Kai-shek, e o Partido Comunista Chinês (PCCh), liderado por Mao Zedong. Enfim, os nacionalistas do KMT se refugiaram em Taiwan, com a chegada do PCCh ao poder e com a fundação da República Popular da China (RPC), em 1949.

A política de isolamento da RPC foi expressa em 1951, quando os EUA utilizaram seu poder de veto para barrar a entrada da China continental nas Nações Unidas e continuaram a reconhecer Taiwan na organização. Além disso, os EUA firmaram, em dezembro de 1954, o Tratado de Defesa Mútua com Taiwan e, desde então, assumiram a responsabilidade pela defesa da ilha, em caso de ataques (LAFEBER, 1994, p. 553).

A tradição de não reconhecimento e de contenção do Estado chinês foi continuada pelos governos posteriores e vista como necessária, diante do teste de bomba atômica pela China, em 1964, no contexto da Guerra Fria. Entretanto, indícios de que mudanças eram conjecturadas cresciam: em 1966, o Comitê de Relações Exteriores do Senado realizou audiências, debatendo a necessidade de uma nova política dos EUA para a China, em um contexto de crescente desgaste entre a URSS e a China (MANN, 2000, p. 18; SHAMBAUGH, 1996, p. 182).

Assim, em 1968, quando a política externa da China ganha traços mais definidos e uma atuação mais flexível nas relações exteriores é decidida pelo PCCh, os EUA, que vinham recebendo críticas à política de contenção, especialmente no contexto da Guerra do Vietnã, estavam prontos para reavaliar a estratégia que vinha sendo empregada desde o início da Guerra Fria. Nesse sentido, a aproximação com a China se tornou uma prioridade política para os EUA, especialmente a partir da cisão sino-soviética, em 1969 (LEITE, 2005, p. 54).

Foi através de um canal não-oficial de comunicação, por meio do presidente do Paquistão, Yahya Khan, que a China expressou seu interesse em discussões de alto nível com representantes dos EUA. Assim, após meses de preparação, Henry Kissinger, Conselheiro de Segurança Nacional, viajou à China em julho de 1971 para acertar a então futura viagem de Richard Nixon, presidente dos EUA. Tinha início a era de engajamento e de normalização das relações com a viagem oficial de Nixon para a China e seu encontro com Zhou Enlai, em 1972. Após uma semana de negociações entre os representantes, foi divulgado o Comunicado de Shangai, que elencava 16 pontos da visão chinesa e estadunidense sobre política internacional e demonstrava o desejo de maior cooperação cultural e econômica, bem como o estreitamento dos laços políticos entre os países. Tal encontro também é compreendido como uma mensagem aos soviéticos, mais do que nunca afastados da RPC (LAFEBER, 1994, p. 649; LEITE, 2005, p. 62). 
Contudo, a situação doméstica nos EUA não foi favorável para o andamento das relações. Os escândalos de Watergate e uma série de acontecimentos em política externa enfraqueceram a autoridade de $\mathrm{Ni}$ xon, até a sua renúncia em agosto de 1974, e dificultaram o processo de normalização das relações, ainda mais em um contexto em que a cúpula do poder na China estava dividida, em relação às opções de estratégias de desenvolvimento a serem seguidas pelo país, anos após o falecimento de Mao Zedong (LEITE, 2005, p. 64).

Assim, foi somente na administração do presidente Jimmy Carter que as relações diplomáticas com a China foram, enfim, retomadas. Isso ocorreu no contexto de abertura da China ao exterior, a partir de 1978, por meio de reformas econômicas e políticas encabeçadas por Deng Xiaoping. As negociações para o reestabelecimento oficial das relações entre os EUA e China foram retomadas e concluídas com o Comunicado Conjunto sobre o Estabelecimento de Relações Diplomáticas entre os EUA e a China, de 15 de dezembro de 1978, com a previsão de troca de embaixadas para o ano seguinte.

Os anos 1980 são considerados como a "era de ouro" das relações sino-americanas, com encontros de alto nível, avanços econômicos, renovação anual do status de nação mais favorecida para a China e transferência de armas e tecnologias dos EUA para a RPC. Porém, tal quadro foi abalado com o episódio da Praça da Paz Celestial, quando, em 3 de junho de 1989, o Exército de Libertação Popular avançou por Pequim até alcançar a praça em que manifestantes pró-democracia estavam concentrados, valendo-se de uma brutalidade que levou a inúmeras mortes e à repressão do movimento pró-democracia na China (MANN, 2000, p. 183-186).

A partir de então, o Congresso e a opinião pública nos EUA impediriam, de todas as maneiras, uma relação amistosa com a China. A administração de George $\mathrm{H}$. Bush suspendeu a venda de armas para Pequim no imediato pós-crise e passou a articular maneiras de congelar a ajuda financeira fornecida à RPC por organizações internacionais, como o Banco Mundial. Foi somente em 1991 que o presidente Bush aceitou encontrar-se com representantes chineses, em um contexto em que o tema de direitos humanos passou a ocupar mais espaço na agenda de negociações bilateral (LEITE, 2005, p. 82).

A década de 1990 foi marcada pelo aprofundamento das relações comerciais e, pela primeira vez desde a retomada das relações com os EUA, a China era percebida como um poder econômico global no Pós-Guerra Fria. Observa-se o início de uma conjuntura que passaria a preocupar os dirigentes estadunidenses sob a administração de William (Bill) Clinton: integrar a China no sistema internacional era essencial para que ela "jogasse as regras do jogo”. É nesse contexto em que se dão as negociações para a entrada da China na Organização Mundial do Comércio (OMC), nos anos 1990, e a concessão do status de relações comerciais normais permanentes entre EUA e China, em setembro de 2000, até sua entrada formal na OMC, em 2001.

A administração de George W. Bush tinha como principal objetivo, no âmbito da política externa, uma nova estratégia global coerente com o poderio da considerada única superpotência, no caso, os 
3. Como, por exemplo, quando do impasse sobre a responsabilidade da colisão entre uma aeronave da Marinha dos EUA, um modelo EP-3 que realizava uma missão de reconhecimento sob o Mar do Sul da China, com um jato F-8 da Força Aérea chinesa, que fazia o patrulhamento da região junto com outro jato do mesmo modelo.
EUA. Um dos pilares dessa nova estratégia era a chamada nova política para a Ásia, baseada nas percepções de que aquela era uma região de prováveis conflitos nos próximos anos e de que era necessário lidar com a China, o novo desafio econômico e estratégico dos EUA (LEITE, 2005, p. 92). Assim, a administração Bush passou a perseguir uma estrutura de segurança regional na Ásia, cuja ideia principal era conter a China, de forma a impedir que ela se tornasse uma potência regional dominante.

A relação bilateral foi marcada, nos primeiros meses da administração Bush, por desgastes ${ }^{3}$ e foi somente no pós-11 de setembro de 2001 que uma maior cooperação entre os EUA e a RPC se deu. No contexto de profundo envolvimento com guerras da Doutrina Bush e da Guerra Global Contra o Terror, rivalizar com a China não era uma opção para os EUA. O presidente Bush tomou a decisão de alinhar-se com os membros de sua administração que eram favoráveis ao engajamento com a China, “(...) embora o Secretário de Defesa Donald Rumsfeld tenha bloqueado a restauração das relações militares diretas por alguns anos" (BADER, 2012, p. 20).

Nesse contexto, é possível observar a substituição do termo "competidor estratégico" por "parceiro estratégico" na Estratégia de Segurança Nacional (NSS) de 2002, documento no qual a administração Bush afirmava o interesse em constituir agendas para ação cooperativas com "outros centros principais de poder global", com destaque para a China e a Rússia (UNITED STATES OF AMERICA, 2002). Os anos vindouros foram marcados por esforços voltados para a promoção da cooperação bilateral e por mais de 19 encontros, entre 2002 e 2006, entre os presidentes chinês Hu Jintao e Bush.

Um esforço de institucionalização das relações nesse período foi o China-U.S. Strategic Economic Dialogue (SED), estabelecido em 2006, visando aumentar o diálogo entre os presidentes em questões econômicas e comerciais, principalmente, em um panorama em que o Congresso estadunidense passava a discutir mais enfaticamente questões relacionadas ao desequilíbrio comercial bilateral e a questionar a política cambial chinesa (JIN, 2010, p. 71-72). Vale notar que o último ano em que os EUA tiveram um superávit em bens com a China foi em 1982 (como indicado na figura abaixo) e, de 1983 a 2006, o déficit passou de US\$ 68 milhões para US\$232.5 bilhões, chegando a US\$ 419.2 bilhões em 2018. Tais preocupações cresceram nos anos seguintes, com a China se tornando a maior detentora de reservas estrangeiras do mundo e a maior financiadora externa do Tesouro norte-americano. 


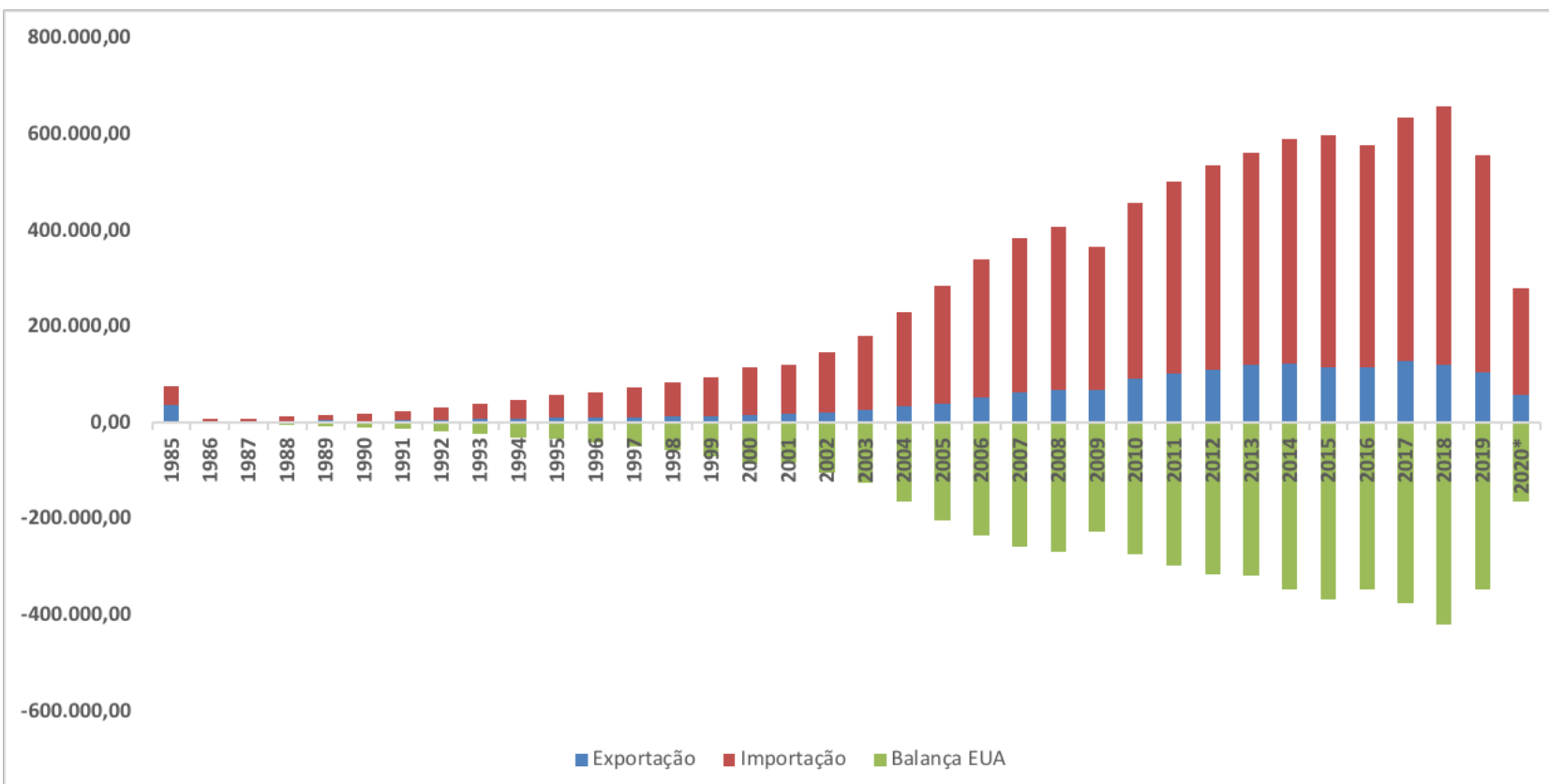

Fonte: elaboração própria com base em dados de United States Center Bureau (2020)

*dados de 2020 referentes a janeiro-julho

Assim, como lidar com a China era, cada vez mais, a pergunta central nos círculos dirigentes estadunidenses. Uma "simples" estratégia de contenção, como no início da Guerra Fria, seria contraproducente e irreal naquele contexto, mas como continuar com a política de engajamento para contenção, por exemplo, levando em consideração o espaço conquistado pela China? É com tais elementos em mente que os próximos tópicos focam nas administrações de Obama e Trump, respectivamente, observando como a política para a China foi um grande componente da grande estratégia estadunidense entre 2009 e 2020, ressaltando os impasses dessa política e o crescente consenso bipartidário por medidas mais duras em relação à China.

A grande estratégia sob Obama: o pivôn para a Ásia

No presente tópico, discute-se as prioridades da grande estratégia estadunidense sob a administração Obama (2009-2016) e, principalmente, a política para a China nesse contexto. Destaca-se o aprofundamento da estratégia de constrangimento da República Popular da China (RPC) às regras e normas criadas pelos Estados Unidos (EUA), o que foi expresso com a maior presença estadunidense na Ásia, no pivô para a Ásia, e com iniciativas como a Parceria Transpacífico. Para além, o tópico busca demonstrar o crescimento das demandas internas por medidas mais duras em relação à China, elemento essencial para o olhar posterior para a administração de Donald Trump.

Como apontado por Martel (2015, p. 325), a primeira prioridade da grande estratégia dos EUA sob Barack Obama seria a reconstrução dos fundamentos domésticos do poder estadunidense. Mas isso precisava ser 
realizado em um panorama de diversos pontos críticos, com a sobreposição de prioridades, especialmente no que estava relacionado à política externa. Foi nesse contexto que a equipe de Obama avaliou que a percepção na Ásia, em 2009, era que os EUA haviam se distraído com em sua Guerra ao Terror e que estavam economicamente enfraquecidos (BADER, 2012, p. 2). A ausência de altos representantes estadunidenses, em fóruns regionais nos anos antecessores, e a insistência de debates sobre terrorismo, em fóruns econômicos, eram apontados como evidências da falta de prioridade dos EUA para a região.

A partir desse assessoramento, a administração Obama começou a traçar uma política de resgate da presença estadunidense na Ásia em geral. Ainda nos primeiros meses, Obama assinou o Tratado de Amizade e de Cooperação da Associação de Nações do Sudeste Asiático (ASEAN), bem como estimulou uma maior circulação de representantes estadunidenses nas diversas organizações regionais asiáticas (BADER, 2012, p. 3-4). Mas, ainda nesse contexto, o maior desafio geoestratégico em relação à Ásia era, sem dúvidas, como lidar com a China.

Nesse sentido, a estratégia de contenção não era uma opção: a RPC estava efetivamente integrada à economia global, um movimento apoiado pelos EUA, desde a administração Nixon; e uma política de acomodação face a uma China mais assertiva também não seria prudente, especialmente para os aliados estadunidenses na região. Uma política multifacetada, portanto, era necessária (BADER, 2012, p. 7). James Steinberg, subsecretário de Estado, tornou-se um nome proeminente nesse período, introduzindo o conceito de reafirmação estratégica (strategic reassurance) para caracterizar a relação bilateral. Em discurso proferido em setembro de 2009, Steinberg afirmou que um acordo básico deveria pautar a relação entre os EUA e a China, de forma a saudar a chegada da China, que se desenvolveria e se integraria, no sistema internacional, de forma pacífica.

Obama e Hu Jintao se encontraram pela primeira vez, em abril de 2009, durante a reunião do Grupo dos Vinte (G-20), em Londres, na esteira da crise de 2008. Nesse encontro, os presidentes acertaram um programa de fomento ao crédito e de recuperação econômica que ultrapassou o montante de US\$ 1,1 trilhão. Esse momento é entendido, por diversos analistas, como um ponto de virada nas relações entre EUA e China: para Hart et al. (2017, p. 46), a interação entre esses dois Estados, no que concernia à governança global nas últimas décadas, consistia basicamente no apoio estadunidense à entrada da China em organizações internacionais; mas, com a crise, a China foi chamada por Hank Paulson, então secretário do Tesouro, para apoiar o G-20, como um grupo de coordenação para a formulação de respostas à crise.

Ainda às margens do G-20, EUA e China aprofundaram os mecanismos de concertação em alto nível, com o estabelecimento do U.S.-China Strategic and Economic Dialogue (S\&ED). Os encontros anuais permitiriam que diversos altos representantes de ambas as nações pudessem discutir temas principalmente securitários e econômicos, expandindo o escopo estabelecido pelo SED, em 2006 (BADER, 2012, p. 22).

Obama visitou o continente asiático em novembro de 2009, momento em que ganhou destaque sua viagem para a China e os contornos 
da política dos EUA para tal Estado, em específico. Em visita de quatro dias, o presidente dos EUA encontrou-se com o presidente chinês e ambos expediram um comunicado conjunto que celebrava os quase 30 anos de retomada das relações diplomáticas entre seus países e que expressava os desejos mútuos de avanço na cooperação bilateral (THE WHITE HOUSE, 2009). Nessa mesma oportunidade, Obama negou que os EUA buscassem conter tal país ou restringir seu crescimento.

Em meio aos esforços de criação de confiança mútua, “(...) as vozes da oposição, nos EUA, que sempre estiveram em disputa, no que diz respeito ao relacionamento sino-americano, uma vez mais passaram a contribuir para o questionamento da postura do governo e tentar 'empurrar' para uma conduta mais linha-dura” (MAGNOTTA, 2019, p. 85). O déficit comercial com a China crescia e, nesse contexto, certos segmentos nacionais estadunidenses, com destaque para a agricultura e para a indústria, passaram a vocalizar mais as suas demandas, na busca por proteção de seus segmentos.

É nesse contexto que uma nova estratégia é delineada pela administração Obama, que tentou equacionar as diferentes perspectivas sobre como lidar com a China, ao longo de 2010, com o chamado pivô para a Ásia (pivot to Asia). O pivô é resumido em seis linhas de ação: 1) fortalecimento das alianças de segurança bilaterais; 2) aprofundamento das relações de trabalho com as potências emergentes, incluindo a China; 3) engajamento em instituições regionais multilaterais; 4) expansão do comércio e do investimento; 5) ampla presença militar; 6) promoção da democracia e dos direitos humanos (CLINTON, 2011).

Havia um esforço de redirecionamento da grande estratégia estadunidense, pois o terrorismo não era a única ameaça ao Estado. O pivô seria, assim, a transição geopolítica das estratégias dos EUA pós-11 de setembro para um futuro pacífico, com um

\footnotetext{
enfoque ambíguo entre cooperação e contenção, cumprimentos e punhais, orientado, por um lado, pela formação de uma 'malha de contenção' entre diferentes nações asiáticos em bloco, pelo envio de tropas estadunidenses para a região e pelo trabalho, a partir de fóruns multilaterais, para a resolução de conflitos territoriais e de soberania, para também forçar políticas comerciais favoráveis aos Estados Unidos e a seus parceiros e aliados (GORNITZ, 2020, p. 220).
}

Assim, tal projeto de reestabelecimento dos EUA, na Ásia, tinha como objetivo, para Pecequilo (2013, p. 120), a contenção direta da China em um quadro de tensionamento na região da Ásia-Pacífico, principalmente no Mar do Sul da China (MSCh), uma região importante para as rotas comerciais marítimas e objeto de disputas entre Estados do entorno asiático $^{4}$. Van Apeldoorn e De Graaff (2016, p. 224) afirmam que, no segundo mandato de Obama, ficou ainda mais claro o quanto o pivô para a Ásia antagonizava a China, em uma estratégia que poderia até mesmo ter acentuado o tipo de comportamento que ameaçava os interesses da política de portas abertas, ameaça que os EUA tanto se empenhavam em evitar.

Ainda no contexto do pivô, os EUA articularam a Parceria Transpacífico (TPP), buscando reforçar seus laços comerciais na Ásia por meio de um mecanismo multilateral. Tal iniciativa demonstrava o comprometimento com a faceta econômica da histórica política de portas abertas, essencial na
4. Em 2010, a então secretária de Estado Hillary Clinton declarou que a questão do MSCh era parte do interesse nacional dos EUA, em um panorama de crescente internacionalização do tema. 
grande estratégia estadunidense. Mais especificamente, o TPP buscou “(...) acelerar as propostas de integração econômica regional para recuperar as cotas de mercado perdidas pela rápida e sustentada emergência econômica da China” (GOERNITZ, 2020, p. 225), que não foi incluída nas negociações iniciais e só poderia se juntar caso passasse a aderir a princípios que estavam muito distantes de sua prática, em matéria de investimento e comércio (VAN APELDOORN; DE GRAAFF, 2016, p. 217-218, p. 224).

Mudanças profundas ocorreram nos anos seguintes. Obama perdeu grande parte do apoio do Congresso e, além do crescente desgaste interno, passou a enfrentar uma série de questões internacionais urgentes, em seu segundo mandato, como a guerra civil na Síria. Mas a região da Ásia-Pacífico continuava no centro da agenda, com ênfase em questões envolvendo a China na NSS de 2015. Destaca-se a importância dada ao TPP e ao MSCh, onde a presença militar estadunidense era percebida como essencial, para garantir os interesses dos EUA e de seus aliados, expressos na liberdade de navegação e de sobrevoo, face a um maior protagonismo chinês (UNITED STATES OF AMERICA, 2015).

Entretanto, medidas foram tomadas para que os impasses e as disputas territoriais não escalassem para uma situação de confronto aberto, com Susan Rice, conselheira de Segurança Nacional, requerendo que oficiais militares estadunidenses diminuíssem a retórica agressiva, em relação à China. A criação de um mecanismo de diálogo conjunto para tratar de questões relativas a crimes cibernéticos é apontada como um sinal de progresso, após constantes acusações de apoio chinês às atividades de espionagem e roubo de dados nos EUA. Além disso, o presidente chinês Xi Jinping visitou os EUA, em setembro de 2015 e

ambos os países confirmaram sua parceria, em questões como Afeganistão, mudança climática e operações de paz da ONU, além do fortalecimento da cooperação em segurança cibernética, concordando em não conduzir ou apoiar roubo de propriedade intelectual por meios cibernéticos (LOFFLMANN, 2016, p. 103).

Tais elementos são importantes para se compreender como a China foi, nesse período, essencial na grande estratégia dos EUA. Obama buscou recuperar o ritmo de crescimento econômico e reconstruir os fundamentos domésticos do poder estadunidense, em um panorama em que os EUA não diminuíram a sua atuação no sistema internacional. Pelo contrário, a administração Obama é marcada por um evidente esforço de resgate da presença estadunidense na Ásia, de forma geral, mas principalmente como forma de conter a presença chinesa e de assegurar a segurança dos aliados estadunidenses na região (BADER, 2012; GOERNITZ, 2020).

Nesse sentido, Obama buscou a continuidade da política de engajamento com a China para a contenção desse Estado, embora com uma política multifacetada, que foi cristalizada no pivô para a Ásia e, principalmente, no TPP, iniciativas pensadas no sentido de constranger a China às regras criadas pelos EUA. O final do mandato de Obama, entretanto, foi marcado por uma profunda discussão sobre rumos dos EUA e, especialmente, sobre a melhor estratégia para lidar com a China.

Nesse contexto, o presidente eleito Donald Trump assumiu a presidência, em janeiro de 2017, com um discurso de preservação da proemi- 
nência estadunidense e de implementação de uma política mais dura em relação à China, acusada, entre outros, de manipulação cambial, roubo de propriedade intelectual e comércio desleal com os EUA (NGUYEN, 2017, p. 36). Desde então, Trump buscou evidenciar que o pivô para a Ásia havia sido uma característica da administração Obama e que sua gestão formularia sua própria agenda para lidar com a China, tema do último tópico do artigo.

A grande estratégia sob Trump e a política para a China

O tópico discute a grande estratégia estadunidense sob a administração Trump (2017-2020) e, mais especificamente, os principais elementos da política para a China. Entende-se que houve uma mudança estratégica em relação ao período Obama com o fim do pivô para a Ásia, a saída da Parceria Transpacífico (TPP) e a aplicação de tarifas na política bilateral; mas isso é entendido como uma mudança de meios e não de fins, uma vez que os Estados Unidos (EUA) continuaram a buscar pela primazia de seu poderio no sistema internacional com novas iniciativas, sob a perspectiva do "America First".

Ainda durante sua campanha, o candidato republicano Donald Trump ressaltava como os EUA precisavam recuperar o poderio dos EUA e, principalmente, aumentar o uso de seu poder para influenciar a China, com negociações mais duras, principalmente nos assuntos econômicos (SUTTER, 2017, p. 31). Assim, ele foi eleito com expectativas de distanciamento de acordos multilaterais que aproximassem os dois países e, sobretudo, de maior pressão por parte dos EUA, no que concernia ao desenvolvimento de tecnologia de ponta pela China.

A saída dos EUA do TPP aconteceu nesse panorama, ainda em 2017, em um contexto em que a política econômica para a região da Ásia-Pacífico estaria “(...) imbricada em uma 'lógica dura' de represálias aplicadas unilateralmente sobre alguns comportamentos danosos aos interesses nacionais estadunidenses" (GORNITZ, 2020, p. 232). Assim, ainda segundo Gornitz (2020), a malha de contenção criada sob o governo Obama foi desarticulada sob Trump, para dar lugar à renegociação dos laços bilaterais dos EUA com as nações asiáticas e isso não foi diferente no trato com a China.

Apesar do discurso de Trump em relação à China ter sido suavizado no período inicial de sua administração, as principais expectativas de recrudescimento das relações foram se concretizando. Ainda em meados de 2017, o presidente Trump reforçou sua insatisfação com a China, e o encontro do U.S.-China Comprehensive Economic Dialogue, que substituiu o S\&ED, não levou à formação de um acordo sobre medidas para diminuir o déficit comercial entre os dois países (SUTTER, 2019, p. 3). Nesse contexto, a administração Trump passou a considerar a China como um competidor estratégico na NSS de dezembro de 2017, o que parecia evidenciar o início de uma política mais agressiva para tal país.

Tal documento classificou a China como um Estado revisionista, que estaria competindo contra os EUA e seus aliados e parceiros, bem como a Rússia, o Irã e a Coreia do Norte. A NSS constatava, ainda, que a 
China realizava manobras para pressionar sua agenda securitária e política a outros países, como, por exemplo, com investimentos maciços em obras de infraestrutura e esforços para construção de postos militares no Mar do Sul da China (UNITED STATES OF AMERICA, 2017, p. 46).

$\mathrm{O}$ ano de 2018 foi o ano com trabalhos legislativos mais assertivos em relação à China, desde o episódio da Praça Celestial, em 1989. O Congresso realizou diversas audiências sobre os riscos que a China trazia aos EUA, nos mais diversos âmbitos, e passou a exigir, por meio de cartas de seus líderes bipartidários ao Executivo, respostas mais duras em relação à China (SUTTER, 2019, p. 4). Nesse contexto, o Executivo passou a atuar principalmente através de Wilbur Ross, secretário de Comércio, e Robert Lighthzier, representante comercial dos EUA, na chamada guerra comercial com a China.

A aplicação de tarifas comerciais se tornou a regra, alcançando os maiores números desde a Lei Tarifária Smoot-Hawley na Grande Depressão (ZUMBRUN; DAVIS, 2020). A primeira rodada de tarifas ocorreu em março de 2018: $10 \%$ em importações de alumínio e $25 \%$ de ferro chinês, com a China retaliando no mês seguinte, com tarifas de aproximadamente $25 \%$ em diversos produtos dos EUA. A imposição de mais tarifas foi divulgada, em julho e em agosto de 2018, com base na Seção 301 da Lei de Comércio de 1974, e, em setembro, um terceiro pacote de tarifas foi aplicado, com impacto adicional de mais de US\$200 bilhões nas importações chinesas. O ano de 2019 foi marcado por tentativas de negociação frustradas, com ameaças de aumento das tarifas por parte dos EUA e com a classificação da China como um manipulador cambial. Foi somente em outubro de 2019 que o presidente Trump anunciou a intenção de maiores esforços conjuntos para um acordo comercial com a China e a retirada do país da classificação de manipulador cambial (SUTTER, 2019; GORNITZ, 2020).

A assinatura da primeira fase do acordo comercial, firmado entre os EUA e a China, se deu somente em 15 de janeiro de 2020. Intitulado "Economic and Trade Agreement between the Government of the United States of America and the Government of the People's Republic of China", o documento, dividido em oito capítulos, trata de temas como propriedade intelectual, transferência de tecnologia e comércio de produtos agrícolas, dentre outros, com destaque para o compromisso chinês de aumentar, em pelo menos US\$ 200 bilhões, a importação de bens agrícolas e manufaturados dos EUA, até 31 de dezembro de 2021 (UNITED STATES TRADE REPRESENTATIVE, 2020).

Tal documento pode ser entendido como uma vitória do estilo de negociação trumpista, mas os efeitos das tarifas e do próprio acordo não parecem ter alcançado, com sucesso, as promessas de campanha de Donald Trump. As tarifas podem ter impactado na diminuição do déficit comercial dos EUA com a China em 2019, como se observa na figura já mencionada, mas seu efeito foi de curto prazo; além disso, tal estratégia não contribuiu para o fortalecimento dos empregos no setor industrial nos EUA (ZUMBRUN; DAVIS, 2020).

Questões estruturais, portanto, permanecem: "a redução do 'emprego industrial' não decorre da imigração ou do comércio internacio- 
nal, mas, sobretudo, da automação e de um processo de transnacionalização da produção colocado em marcha na década de 1970" (MARIUTTI, 2019, p. 7). Assim, o principal desafio contemporâneo de Washington seria o de preservar a relação entre a busca da superioridade militar e a sua liderança no setor de alta tecnologia, o que depende, em grande medida, da supremacia do dólar como principal moeda de transação internacional.

Nesse sentido, Mearsheimer (2019, p. 46-47) afirma que pouco pode ser feito para resgatar a ordem internacional liberal que pautou as últimas décadas e que os EUA estariam travando uma verdadeira guerra hegemônica enquanto ainda estão em condição de competir com a China. Logo, "as duras medidas econômicas da administração Trump, em relação à China, são apenas o começo do que promete ser uma intensa e longa competição entre as ordens lideradas pelos EUA e pela China” (MEARSHEIMER, 2019, p. 47).

O documento de maio de 2020, que delineia a estratégia dos EUA para lidar com a China, reforça tal entendimento. Intitulado "United States Strategic Approach to the People's Republic of China", a peça ressalta o caráter competitivo da relação bilateral e retoma as orientações da NSS de 2017: a estratégia competitiva dos EUA estaria baseada, segundo o documento, no fortalecimento das instituições domésticas e das parcerias e alianças para lidar com o desafio chinês e na busca pela mudança de práticas de Pequim, consideradas nocivas e desleais em relação aos interesses estadunidenses (UNITED STATES OF AMERICA, 2020).

Nesse sentido, o relatório destaca os esforços domésticos de investigação e de combate, principalmente por parte do Escritório do Representante de Comércio dos EUA (USTR), a ações como transferência de tecnologia de empresas dos EUA para contrapartes chinesas, desrespeito à propriedade intelectual e baixa reciprocidade nas relações bilaterais. $\mathrm{O}$ fortalecimento do Committee on Foreign Investment in the United States (CFIUS), grupo interagência, também é ressaltado, principalmente a partir do aumento do seu poder regulatório com o Foreign Investment Risk Review Modernization Act (FIRRMA), de 2018, em um contexto de revisão de acordos e de aumento dos mecanismos de controle de exportações para a China (UNITED STATES OF AMERICA, 2020). Por fim, vale mencionar como a Iniciativa do Cinturão e Rota aparece, no documento, como um termo guarda-chuva para incluir uma diversidade de iniciativas chinesas, as quais privilegiam o uso e a expansão de padrões industriais chineses em setores chaves, principalmente tecnológicos, contra os quais os EUA não deixarão de combater no futuro mais imediato e de longo prazo.

Como discutido, Washington buscou endurecer sua política para a China e atuar a partir de uma posição de força, como apresentado em diversos documentos da administração Trump, mas os resultados das decisões são sempre dependentes de relações de poder, tanto na esfera doméstica, quanto na internacional. E é nesse sentido que as análises precisam levar em consideração não somente a conjuntura, mas também um olhar sob uma perspectiva histórica e a dinâmica e correspondências entre o setorial e o global. 
Considerações finais

O presente artigo buscou discutir e analisar a grande estratégia estadunidense, entendida como as coordenadas gerais que pautam a conduta desse Estado no sistema internacional, e a política setorial dos Estados Unidos (EUA) para a China, a qual assume um caráter de destaque na grande estratégia dos EUA. Buscou-se demonstrar a tendência de continuidade nos governos de Barack Obama e de Donald Trump, entre 2009 e 2020, no sentido de fortalecimento de iniciativas na busca pela manutenção do poderio estadunidense no sistema internacional, face ao maior protagonismo e desenvolvimento econômico chinês.

Para tanto, o primeiro tópico dedicou-se à temática da grande estratégia e à operacionalização de seu estudo a partir de políticas setoriais, que sustentam e imprimem legitimidade à grande estratégia, ao longo do tempo. O segundo tópico do artigo buscou justamente analisar a grande estratégia dos Estados Unidos a partir de um olhar histórico, resgatando seus grandes marcos, e como a China esteve presente nela. Foram destacadas as políticas de contenção e de engajamento daquele Estado pelos EUA, de forma a proporcionar as bases para uma análise dos governos Obama e Trump a partir de uma perspectiva de longo prazo.

Assim, o terceiro e quarto tópicos do artigo analisaram a política propriamente dita dos EUA para a China, nas administrações dos presidentes democrata e republicano, respectivamente. Evidenciou-se a tendência de iniciativas mais duras no sentido de constrangimento da China, principalmente com um crescente consenso bipartidário doméstico a iniciativas como o pivô para a Ásia e a Parceria Transpacífico (TPP) sob Obama. Evidentemente, o presidente Trump optou pela retirada dos EUA do TPP, em um contexto de questionamento de diversos fundamentos da grande estratégia estadunidense, mas sua administração não deixou de lado a Ásia e, mais especificamente, a China, em um cenário de recrudescimento das relações bilaterais e de crescente disputa hegemônica entre esses Estados.

Referências

ALLISON, G. T. Conceptual Models and the Cuban Missile Crisis. The American Political Science Review, v. 63, n. 3, p. 689-718, 1969.

ART, R. J. America's Grand Strategy and World Politics. New York: Routledge, 2009.

BADER, J. Obama and China’s Rise: An Insider's Account of America's Asia Strategy. Washington, DC: Brookings Institution Press, 2012.

CLINTON, H. America’s Pacific Century. Foreign Policy. 2011. Disponível em: http://foreignpolicy.com/2011/10/11/americas-pacific-century/. Acesso em: 21 de jul. 2020.

CRUZ, S. C. V. Os Estados Unidos no desconcerto do mundo: Ensaios de interpretação. Editora Unesp, 2012.

MARTEL, W. Grand Strategy in Theory and Practice: The Need For an Effective American Foreign Policy. Cambridge: Cambridge University Press, 2015.

GORNITZ, L. Rupturas y continuidades de la política exterior estadunidense hacia la República Popular China: Del Pívot a Asia y El Pacífico a "America First" (2011-2018). In: SANTILLÁN, G.; MINA, F. Las relaciones exteriores de China: perspectivas históricas. Córdoba: Editorial de la UNC. Facultad de Filosofía y Humanidades, p. 214-247, 2020. 
HART, B. H. L. Strategy. London, England: Meridian, 1967.

HART, M.; ECONOMY, E. C.; GEWIRTZ, P. Global Governance Issues in U.S.-China Relations. Joint U.S.-China Think Tank Project on the Future of U.S.-China Relations: An American Perspective, p. 45-51, 2017.

HILL, C. The changing politics of foreign policy. Hampshire/New York: Palgrave McMillan, 2003.

LAFEBER, W. The American age: U.S. foreign policy at home and abroad. New York, London: W.W. Norton \& Company, 1994.

LEITE, D. F. S. A política externa dos Estados Unidos para a China: Contenção pelo Engajamento. Recife, 2005. 111f. Dissertação (Mestrado em Ciência Política). Centro de Filosofia e Ciências Humanas, Universidade Federal de Pernambuco.

LOFflmanN, G. The Pivot between Containment, Engagement, and Restraint: President Obama’s Conflicted Grand Strategy in Asia. Asian Security, v. 12, n. 2, p. 92-110, 2016.

MAGNOTTA, F. P. A política dos Estados Unidos para a China na América Latina no início do século XXI: acomodação versus confrontação. São Paulo, 2019. 184f. Tese (Doutorado em Relações Internacionais). Programa de Pós-Graduação em Relações Internacionais San Tiago Dantas, UNESP/UNICAMP/PUC-SP.

MANN, J. About Face: A History of America’s Curious Relationship with China, from Nixon to Clinton. New York: Vintage Books, 2000.

MARIUTTI, E. B. Os EUA e a Ordem Internacional Contemporânea: notas. Panorama EUA, v. 9, n. 2, p. 1-11, 2019.

MEARSHEIMER, J. J. Bound to Fail: The Rise and Fall of the Liberal International Order. International Security, v. 43, n. 4, p. 7-50, 2019.

MULLER, P. Un schéma d'analyse des politiques sectorielles. Revue Française de Science Politique, v. 35, n. 2, p. 165-189, 1985 .

NGUYEN, H. The US China policy under Trump: Change in Continuity. Russian Journal of Political Studies, v. 3, n. 1, p. 30-41, 2017.

PECEQUILO, C. S. Os Estados Unidos e o século XXI. Rio de Janeiro: Elsevier Editora, 2013.

SHAMBAUGH, D. Containment or Engagement of China? Calculating Beijing's Responses. International Security, v. 21, n. 2, p. 180-209, 1996.

SUTTER, R. Trump's China Policy: Bi-partisan Hardening, Uncertain Resolve. H-Diplo/ISSF Policy Series: America and the World - 2017 and Beyond, p. 1-13, 2019.

THE WHITE HOUSE. U.S.-China Joint Statement. 2009. Disponível em: https://obamawhitehouse.archives.gov/realitycheck/the-press-office/us-china-joint-statement. Acesso em: $21 \mathrm{de}$ jul. 2020.

UNITED STATES CENTER BUREAU. Trade in Goods with China. 2020. Disponível em: https://www.census.gov/foreign-trade/balance/c5700.html\#1986. Acesso em: 14 set. 2020.

UNITED STATES OF AMERICA. National Security Strategy of the United States of America. Washington: The White House, 2002.

UNITED STATES OF AMERICA. National Security Strategy of the United States of America. Washington: The White House, 2017.

UNITED STATES OF AMERICA. National Security Strategy. Washington: The White House, 2015.

UNITED STATES OF AMERICA. United States Strategic Approach to the People's Republic of China. The White House, 2020.

UNITED STATES TRADE REPRESENTATIVE. Economic And Trade Agreement Between The Government Of The United States Of America And The Government Of The People's Republic Of China. Office of the United States Trade Representative, 2020.

VAN APELDOORN, B.; DE GRAAFF, N. American Grand Strategy and Corporate Elite Networks: The Open Door since the end of the Cold War. London and New York: Routledge, 2016.

WILLIAMS, W. A. The Tragedy of American Diplomacy. New York: W. W. Norton, 2009.

ZUMBRUN, J.; DAVIS, B. China Trade War Didn't Boost U.S. Manufacturing Might. The Wall Street Journal. 2020. Disponível em: https://www.wsj.com/articles/china-trade-war-didnt-boost-u-s-manufacturing-might-11603618203. Acesso em: 27 out. 2020. 